\title{
Prevalence of Life Style Drugs Usage and Perceived Effects among University Students in Dar es Salaam
}

\author{
Kennedy D. Mwambete*, Theresia Shemsika \\ Department of Pharmaceutical Microbiology, Muhimbili University of Health and Allied Sciences (MUHAS), Dar es Salaam, \\ Tanzania \\ *Corresponding author: kmwambete@muhas.ac.tz
}

Received December 27, 2013; Revised April 28, 2014; Accepted May 20, 2014

\begin{abstract}
This was a cross-sectional study involving randomly selected university students from University of Dar es Salaam (UDSM) and Muhimbili University of Health and Allied Sciences (MUHAS). Each respondent filled in a consent form prior to an interview. Awareness and prevalence of LSD usage, perceived effects and personal opinions on LSD usefulness were investigated. A total of 310 students (222 males and 88 females) aged between 21 and 35 years were interviewed. About 56.5\% ( $\mathrm{n}=175)$ were non-medical students from UDSM while 135 (43.5\%) were medical students from MUHAS. Majority (92\%) of the students was aware of LSDs, though only $29.3 \%$ of them had used one of 10 tracer LSDs, while 18 (5.8 \%) students were uncertain whether they had ever used LSDs or not. Over $81 \%$ of LSD users had used alcohols and $43 \%$ of those admitted to have been propelled by peer pressure. Euphoria and "good sleep" were the mentioned by $27 \%$ of LSDs users as motive for consuming them, while $32.5 \%$ said LSDs usage added an extra-financial burden. This is the first study on the prevalence of LDS usage in universities.
\end{abstract}

Keywords: life style drugs, adverse effects, easy availability of drugs

Cite This Article: Kennedy D. Mwambete, and Theresia Shemsika, "Prevalence of Life Style Drugs Usage and Perceived Effects among University Students in Dar es Salaam.” American Journal of Biomedical Research, vol. 2, no. 2 (2014): 29-35. doi: 10.12691/ajbr-2-2-3.

\section{Introduction}

Lifestyle has changed from being an indicator of an overall well-being of an individual to a cause of diseases and now "lifestyle" has itself become an object of medical attention. [1] The change in lifestyle particularly in urban society gave rise to marketing of lifestyle drugs (LSDs). [2,3] The term "lifestyle drug" is an inaccurate term commonly applied to medications which treat non-life threatening and non-painful conditions such as baldness, impotence, wrinkles or acne, which a person perceives as either not medical problems at all or as minor medical problems relative to others. [1,2,3] Therefore, LSDs can also be considered as drugs taken to satisfy a non-medical or non-health-related goal such as improve sexual and academic performances as well as changing and/or improving physical appearance [4-9].

A number of pharmaceutical products/drugs are regarded as LSDs, these include drugs that address erectile dysfunction (Viagra, Cialis), birth control drugs (levora, depo provera), hair loss prevention drugs (propecia/ finesteride), weight-loss drugs (orlistat), smoking cessation drugs (zyban/bupropion) and some cosmeticrelated drugs that may improve appearance, but not necessarily improve health (botox, latisse). Nonetheless some of these drugs might be helpful as a preventive measure for advent of harmful effects of lifestyle such as quitting smoking and losing weight; yet they can't be equated to other curative or life-saving drugs. [10,11,12]

Easy availability of drugs, particularly LSDs, is currently changing the social norms and cultures of various communities in Africa and other parts of the world; this poses a challenge to the healthcare system. $[7,12,13]$ Studies have shown that neuro-pharmaceuticals/LSDs could be used to enhance brain processes in 'normal' people. [14,15] Thus, now medicine/drugs serve as a remedy for improving academic performance or memory, sex life and mood changing. This has completely altered the natural way of learning, feeling or reacting to socioeconomic hardships and cultural rhetoric.

Recently, a term "disease mongering” or "selling of sickness" has emerged, which implies turning "'ordinary ailments" into medical problems, seeing mild symptoms as serious, treating personal problems as medical and seeing risks as diseases. $[7,16]$ There could be medical harm resulting from indiscriminate use of LSDs, like adverse effects, abuse potentialities and safety concerns. This brings up issues of the rights to and limits of, selfdiagnosis, self- medication, internet prescription and direct dissemination of pharmaceutical-related information to consumer [3,17].

Ever since, it is well known that there is no drug without side effects, and that every substance comes with an added risk. [18,19,20] Unluckily neither there is an easy answer nor drug that can fix all of our problems. Consequently, because of students' living environment, 
peer pressures and other socio-economic factors to which they are subjected to; we embarked into investigating on prevalence of LSD usage and perception of the drugs among university students, who always are eager to experiment new stuffs.

\section{Methodology}

\subsection{Study Design and Population}

This was a prospective cross-sectional study involving university students irrespective of their age, sex, year of study (education level) and other social-cultural factors. The study was conducted in Dar es Salaam at two university campuses namely UDSM and MUHAS. The targeted study population was all university students residing at the two campuses.

\subsection{Sampling Procedure}

A sample size of 420 students was estimated based on findings of a pilot study that was carried out at Dar es Salaam University College of Education. A sampling frame of 9,000 and 3,000 students was established for UDSM (Mlimani Campus) and MUHAS respectively. The sample size of 420 students is equivalent to $3.5 \%$ of the total study population of the two universities. Notwithstanding, participants were randomly selected as shortly stated.

\subsection{Data Collection}

A pilot tested questionnaire with both closed and open ended questions was employed for data collection. Each questionnaire was administered to a single student and filled in the presence of pre-trained researchers. Apart from demographic data, the following key aspects were investigated: awareness of LSDs in university community, their impacts and the prevalence of LSDs usage. Most of the approached students volunteered to participate in the study.

To assess awareness the students were asked if they have ever heard of LSDs and what were the sources of information of the same. To assess the usage, the students were asked if they have ever used LSDs in their lifetime or still using. To validate this information, the students were asked to mention and identify them among 10 tracer LSDs, which were categorized by pharmacological groups. This aspect was further complemented by inquiring on sources of the LSDs and on whether the drugs were effective for the intended use or not.

Students were also asked what was/were the motives for using the LSDs and on whether they had experienced any undesired effects as result of LSDs usage. To investigate further on the side effects or adverse effects, the interviewees were asked to mention some of the most common experienced side/adverse effects. Students' opinions regarding LSDs usage were also sought by asking them to state whether they agree, they are not sure or disagree on the following aspects: regular use of LSDs improve life in almost all aspects, whether LSDs could prevent social stigma and isolation, if health personnel should promote LSDs usage, a need exists for LSDs consumption to homogenize the society and finally whether using LSDs for body modeling was acceptable.

\subsection{Ethical Issues}

Permission to conduct this study was granted by responsible authorities from the two university campuses. Objectives of the study were explicitly described to each participant prior administration of the questionnaire. Consenting students were also assured of confidentiality of the volunteered information; thus each questionnaire was coded, names and other personal details were not disclosed.

\subsection{Data Analysis}

The collected and cleaned data were entered into database and analyzed using Statistical Package for the Social Sciences (SPSS version 17.0). Descriptive statistics including cross tabulations, frequencies and explorative analysis were carried out to explore on students' awareness on LSDs, prevalence of LSDs usage, the most commonly used drugs, the reasons for use and the effects of these drugs on various aspects of students' life at the respective campuses. Associations among various predictor -parameters such as age, level of education and sex were also assessed using logistic regression method. Differences among the analyzed variables were considered significant when $\mathrm{p}<0.05$.

\section{Results}

\subsection{Socio-Demographic Characteristics of the Study Population}

Table 1. Socio-demographic characteristics of the respondents

\begin{tabular}{|c|c|c|c|c|c|}
\hline \multirow{2}{*}{\multicolumn{2}{|c|}{ Variable }} & \multicolumn{4}{|c|}{ Institution (\%) } \\
\hline & & UDSM & MUHAS & Total & p-value \\
\hline \multirow{2}{*}{ Gender } & Males & 131 (74.9) & $91(67.4)$ & $222(71.6)$ & \multirow{2}{*}{0.25} \\
\hline & Females & $44(25.1)$ & $44(32.6)$ & $88(28.4)$ & \\
\hline \multirow{5}{*}{ Age group (yrs) } & $15-20$ & $8(4.6)$ & $2(1.5)$ & $10(3.2)$ & \multirow{5}{*}{0.18} \\
\hline & $21-25$ & $131(74.9)$ & $100(74.1)$ & $231(74.5)$ & \\
\hline & $26-30$ & $32(18.3)$ & $26(19.3)$ & $58(18.7)$ & \\
\hline & $31-35$ & $3(1.7)$ & $5(3.7)$ & $8(2.6)$ & \\
\hline & $>35$ & $1(0.6)$ & $2(1.5)$ & $3(1)$ & \\
\hline \multirow{5}{*}{ Year of study } & 1 & $20(11.4)$ & $13(9.6)$ & $33(10.6)$ & \multirow{5}{*}{0.29} \\
\hline & 2 & $85(48.6)$ & $26(19.3)$ & $111(35.8)$ & \\
\hline & 3 & $49(28)$ & 45 (33.3) & $94(30.3)$ & \\
\hline & 4 & $21(12)$ & $38(28.1)$ & 59 (19.0) & \\
\hline & 5 & $0(0)$ & $13(9.6)$ & $13(4.2)$ & \\
\hline
\end{tabular}


The study involved a total of 310 students from the two universities, which is $74 \%$ of the expected sample size. Of those, 175 (56.5\%) students were from UDSM and 135 (43.5\%) students from MUHAS. Of 310 respondents, 222 (71.6\%) were males and $88(28.4 \%)$ were females as shown in Table 1. Majority (74.5\%) of the respondents were 21-25 years old, with median age of 24 years; only a few (1\%) of them were over 35 years of age. The T-test revealed no significant differences with regard to ages among students from the two universities $(\mathrm{p}=0.18)$.

\subsection{Awareness and Prevalence of LSDs Usage}

Majority (91.9\%; $n=287)$ of the students had heard of LSDs and only 25 (8.1\%) students had never heard of them. For those who had heard, 21 (7.4\%) of them had heard through health personnel (as medical need), 80 (27.72\%) from friends/family, 108 (37.89\%) through the media, and 77 (27.02\%) through literature search.

Of 310 students, 91 (29.3\%) had used one or more of the LSDs; of these 72 (79.1\%) were males and 19(20.9\%) females. Majority (70.6\%; $n=219$ ) of the respondents had never used the drugs. Of 91 students who had used LSDs; $15.4 \%(n=14)$ were unknowingly consuming the drugs. The study also enquired on the frequency of LSD usage: $85.8 \%$ said rarely used LSDs, $11.7 \%$ had used once, while $2.6 \%$ used the LSDs daily. Investigating on addiction to LSDs; respondents were asked whether had ever felt strong desire for the drugs. About 34\% of the respondents admitted to have felt strong desire for the drugs they used, $22.1 \%$ rarely felt while $40.3 \%$ had never felt so.

An increase of age unit in male students led to 1.163 times increased of LSD usage as compared to female counterparts (CI =1.054-1.285; $\mathrm{p}=0.013$ ). Male students were 0.617 times less likely to use LSDs for sake of improving their lifestyle $(\mathrm{CI}=0.138-3.239 ; \mathrm{p}=0.012)$.
Likewise, males were 1.181 times uncertain on usefulness of LDSs for society homogenization ( $\mathrm{CI}=0.070-19.877)$. Generally, LSDs users were 1.774 (CI=0.435-7.240) and $2.272(\mathrm{CI}=0.667-7.734)$ times more likely to use LDSs to homogenize the society and encourage/promote LDS usage as compared to those who had never used the drugs.

Similarly, males were 0.562 times less likely to use many LSDs as compared to females $(\mathrm{CI}=0.408-0.775$; $\mathrm{p}=0.001)$. Thus a total number of products consumed differed significantly between males and females $(\mathrm{p}=0.025$; $\mathrm{df}=1 ; \mathrm{F}=5.045$ ). Likewise, a number of LSD used differed significantly among age groups $(p=0.001 ; \mathrm{df}=4$; $F=14.095)$. Age difference, had no significant impact on LSD usage among the students $(\mathrm{p}=0.286 ; \mathrm{F}=1.143)$, controlling for sex.

A negative correlation was evident between a number of LSD used (usage) and age of respondents (Pearson correlation $\mathrm{R}=-0.025 ; \mathrm{p}=0.655$ ). An increase in number of LSD used negatively affected the rationality of LSD usage with an odd ration of 0.852 , though statistically not significant $(\mathrm{p}=0.408)$.

\subsection{The Most Commonly Used LSDs}

The study revealed that alcoholic beverages were the most commonly used LSDs. Approximately 64 (70.3\%) students had used alcohol, while one (1.1\%) respondent had been using antidepressant (Paroxetine) and another used a central nervous system stimulant (Ritalin). Other frequently used LSDs are shown in Table 2.

Because of the multiple responses, neither the frequencies of respondents add up to 310 nor the corresponding percentages tally to $100 \%$. One student might have used more than one of the mentioned LSDs hence counted in both cases.

Table 2. The most commonly used lifestyle drugs by the students

\begin{tabular}{|c|c|c|c|}
\hline LSD & $\begin{array}{c}\text { Frequency } \\
(\%)\end{array}$ & Reason for use & Possible clinical use \\
\hline Alcohol & $64(70.3)$ & $\begin{array}{c}\text { Influence from friends/family Relieve stress and fear } \\
\text { Curiosity Improve sexual performance \& } \\
\text { interpersonal relationship } \\
\end{array}$ & Relieve stress, fear and shyness Relaxation \\
\hline Sildenafil (Viagra) & $8(8.8)$ & Curiosity Improve sex life Influence from friends & $\begin{array}{l}\text { Treatment of male erectile dysfunction in } \\
\text { potential patients Pulmonary hypertension }\end{array}$ \\
\hline Oral contraceptive pills & $10(10.9)$ & Prevent pregnancy Influence from friends/family & $\begin{array}{c}\text { Prevention of pregnancy Treatment of } \\
\text { menstrual disorders }\end{array}$ \\
\hline Orlistat & $5(5.5)$ & Losing some weight/slimming & Managing obesity and overweight \\
\hline Benzodiazepines & $7(7.7)$ & Control sleep pattern, Prescribed for medical reasons & $\begin{array}{c}\text { Treatment of mental distress, epilepsy, } \\
\text { insomnia }\end{array}$ \\
\hline $\begin{array}{c}\text { Cosmetics (eflornithine and skin } \\
\text { depigmenting agents) }\end{array}$ & $9(9.9)$ & $\begin{array}{c}\text { Beautification; light skin implies beauty Medical } \\
\text { reasons }\end{array}$ & $\begin{array}{c}\text { Treatment of facial hirsutism Treatment of } \\
\text { hyper pigmentation }\end{array}$ \\
\hline Cannabis & $17(18.7)$ & $\begin{array}{l}\text { Enhance interpersonal relationship Influence from } \\
\text { friends/family Improve academic performance Quit } \\
\text { alcohol intake }\end{array}$ & $\begin{array}{l}\text { As tetrahydrocannabinol is in clinical trial } \\
\text { for relief of chronic pain and nausea. }\end{array}$ \\
\hline Amphetamines & $4(4.4)$ & Suppressing appetite & $\begin{array}{l}\text { Treatment of narcolepsy and attention } \\
\text { deficit disorder with decreased appetite }\end{array}$ \\
\hline SSRIs (Paroxetine) & $1(1.1)$ & Medical reasons & Antidepressant \\
\hline Bupropion & $2(2.2)$ & Quit smoking & Smoking cessation agent \\
\hline Ritalin (methylphenidate) & $1(1.1)$ & Medical reasons & $\begin{array}{l}\text { For children with attention deficit } \\
\text { Hyperactivity disorder (ADHD). }\end{array}$ \\
\hline
\end{tabular}

SSRI-Selective serotonin re-uptake inhibitor

About $6 \%(n=18)$ of the respondents who were uncertain of the drugs they had been using, more than half of them consumed alcohols $(72.2 \% ; n=13)$ and the rest (27.8\%; $n=5$ ) had been using one of the following drugs: contraceptive pills, Viagra, Ritalin, Orlistat and amphetamines.

\subsection{Factors Ascribed to LSD Usage}

Of 91 (29.4\%) students who had used LDSs; 70.3\% $(n=64)$ of them consumed alcoholic beverages because of peer pressure (pleasure) and to relieve stress/anxiety; while $19 \%(n=15)$ used cannabis to enhance interpersonal 
relationship and improve academic performance (Table 3). The reasons given for consuming LSDs were similar for all age groups.

Table 3. Short-term effects of using LSDs

\begin{tabular}{|c|c|c|}
\hline \multirow{2}{*}{ Aspects } & \multicolumn{2}{|c|}{ Consequences (\%) } \\
\cline { 2 - 3 } & Positive & Negative \\
\hline Sex life & $15(16.5)$ & $9(9.9)$ \\
\hline Carrier plans & $4(4.4)$ & $6(6.6)$ \\
\hline College activities & $7(7.7)$ & $3(3.3)$ \\
\hline Sleep pattern & $21(23.1)$ & $9(9.9)$ \\
\hline Physical and mental health & $17(18.7)$ & $15(16.5)$ \\
\hline Financial status & $0(0 \%)$ & $2527.5)$ \\
\hline Academic performance & $9(9.9 \%)$ & $13(14.3)$ \\
\hline Interpersonal relationship & $17(18.7)$ & $11(12.1)$ \\
\hline
\end{tabular}

\subsection{Perceived Short-term Effects of LSDs Usage}

The results showed that there were good as well as bad effects/consequences of LSDs usage on various arenas of students' lives. A total of 21(23.1\%) students testified that LSDs had good effects especially on their sleep patterns, improvement of their interpersonal relationship $(n=17$; $18.7 \%)$, enhance physical and mental health $(n=17$; $18.7 \%)$. Some of the cited negative effects associated with LSD usage include increased financial burden (expenses), effects on physical and mental fitness and negative impact on academic performance (Table 3 ).

\subsection{Awareness of Adverse Effects and Rating of LSDs Usefulness}

Of 91 students who had been using LSDs, 51 (56\%) acknowledged to have had experienced some adverse and/or side effects. However, only $49 \%(n=25)$ of them were capable of citing the side effects. The most frequently experienced side effects include fatigue (39.2\%; $n=20)$ and impairment of menstrual period (7.8\%; $n=4)$. Impaired sexual performance and decreased libido as well as photophobia; each of these was cited by $6.0 \%(n=3)$ of the LSDs users. While $35.3 \%(n=18)$ had not experienced any adverse effects.

About $66.5 \%(n=206)$ of the students were of opinion that most of the LSDs were unfit for their health. However, 104(33.5\%) interviewees were uncertain on the LSD usefulness to the society or at individual levels. About $45.2 \% \quad(n=140)$ students opinionated that individuals should have control on their lives including physical appearance; other rated aspects have been summarized in Table 4.

Table 4. Students' rating of lifestyle drugs usefulness

\begin{tabular}{|c|c|c|c|}
\hline \multirow{2}{*}{ Opinion } & \multicolumn{3}{|c|}{ Rating (\%) } \\
\hline & Agree & Not sure & Disagree \\
\hline LSDs are generally harmless & $58(18.7)$ & $53(17)$ & $199(63.6)$ \\
\hline LSDs are very effective for their intended use & $109(35.2)$ & $104(33.5)$ & $97(31.3)$ \\
\hline Regular use of LSDs improve life in almost all aspects & $28(9.0)$ & $76(24.5)$ & $206(66.5)$ \\
\hline LSDs can prevent social stigma and isolation & $89(28.7)$ & $94(30.3)$ & $127(41.0)$ \\
\hline Health personnel should promote the use of LSDs & $76(25.0)$ & $64(20.6)$ & $170(54.8)$ \\
\hline LSDs can homogenize the society & $58(18.7)$ & $113(36.5)$ & $139(44.8)$ \\
\hline Modeling someone's body to fit in the society is acceptable & $106(34.2)$ & $79(25.5)$ & $125(40.4)$ \\
\hline Living a life as per one's wish/will is what matters & $140(45.2)$ & $58(18.7)$ & $112(36.3)$ \\
\hline
\end{tabular}

\section{Discussion}

Over the past decade, a number of drugs that address aspects of lifestyle have become widely available, while others have been the subject of lifestyle marketing. [1,5] There are significant negative impacts of LSDs usage on society, particularly in developing countries: from socioeconomic point of view, the scarce financial resources are being wasted on treating non-medical conditions while a number of health facilities are running out of essential drugs/medicines. Another concern regarding LSDs usage is on safety, their effects could be shortly manifested or not. Treating problems that are due to lifestyle choices also has consequences. Not only that LSDs are likely to become products for socio-economically capable individuals, but also can attribute to integrity loss, since using LSDs is cheating, as asserted by the former US President (George W. Bush). One can also speculate that if LSDs can make someone quicker at taking decisions may also make them more careless and impulsive. [4,8,9] Results have shown that some of the LSD adverse effects make students unable to execute their daily academic activities smoothly.

The use of LSDs is associated with myths that people are more in control of their minds, emotions, senses and physical appearance. [21] Alcohol, Sildenafil-a sexual activity enhancer, oral contraceptive pills, cosmetics, cannabis mentioning a few are among the most commonly used LSDs among university students. What they have in common is the ideology that they make the users euphoric and a sensation of being in fully control of their lives. Our study shows that male students use LSDs for pleasure than for "homogenizing the society", which is in concordance with a previous observation. [28]

Respondents revealed substantive awareness of LSDs and their negative impact on their lives. This was manifested by their views against the use of LSDs though only minority was in favor of these drugs. In Tanzania, not only smoking cannabis (marijuana), but also possession or cultivation of marijuana is illegal. Last year, accidentally, it was found that marijuana were cultivated in the vicinity of the campus. It was a time, when at one of the university there was students strike crisis; some of the students acted "violently" in unprofessional manner and against "Tanzanian culture”. Definitely, some of these violent students were under influence of marijuana.

Youths who use alcohol and illicit drugs are more likely to engage in high-risk sexual behavior. [6] In 2010, an incident of a male student cold-bloodedly killed a girlfriend. The act was presumably considered just as love affair '’jealousy lover acting inappropriately'. Such behavior and act might have a direct link with LSD usage. Early age of onset of marijuana use, lifetime frequency of marijuana and alcohol use in African youth has been associated with misconduct and/or multiple sexual partners. [22] In this epoch of HIV/AIDS pandemic, such transgression in university campus becomes a major socio-health concern. Our study shows that males were less likely to use LSD as compared to females, though this 
pattern was changing as age increased. Most of the items that attributed to this tendency were alcoholic beverages and sexual activity enhancing products.

A study conducted in India, showed that taller people do better in sports, play an important role in politics, and they had better chance for employment and choice of marital partners [1,23]. As result several Indian pharmaceutical companies are now producing height increasing pills that for the time being are assumed to be free from any adverse effects. These drugs are purported to be capable of increasing height even after the age of 30 , and are advertised through television channels and newspapers worldwide [1]. Our study has clearly shown a significant role of mass media in negatively shaping our youth as previously reported elsewhere. [17] Obesity and overweight can be managed by diet and lifestyle changes instead of drugs like Orlistat that can induce weight loss in a short time. It has been reported that although people taking Orlistat lose marginally more weight in the short term than those controlling their dietary intake without drug aids; there are no evidences showing that drugs could be any more effective than diet alone in reducing the morbidity and mortality due to obesity $[24,25]$. This is in concordant with our findings, which revealed that over $2 \%$ of the respondents were using the drug for weight loss.

However, orlistat and similar preparations were designed to aid weight loss among obese patients, are sometimes used to manage diet or even to sustain low body weight, while the erectile dysfunction (ED) drug sildenafil (Viagra) has been used by both men and women recreationally to enhance sexual performance. [21,26] In both their medical and non-medical applications, these drugs are associated with intimate personal aspirations concerning sexual satisfaction, appeal and body shape, and affecting particular aspects of normal daily life. [10], [15] The use of Viagra to enhance manhood is something that wouldn't be unexpected among adolescents, who are always eager to experiment new stuff, practicing sex inclusive, under peer pressure. It has also surfaced in the present study. Some respondents clearly stated that it improved interpersonal relationships.

Majority (70.4\%) of the LSD users admitted that alcoholic beverages lifted their moods and reduced stress. The fact is that alcohols could only temporarily make most people feel better. Since it affects neurotransmitters, messenger chemicals in the brain, and the long term effect is depressing not uplifting $[27,28]$.

Nevertheless, it has been demonstrated that behavior predicts an increased likelihood of depression, but not vice versa [29]. There is a need for better education about alcohol, drugs, and general health in universities.

Moreover, some nutrients that are affected by alcohol consumption are the same that help keep the body calm and in control; such as vitamin B complex and mineral zinc. Too much alcohol consumption affects the absorption of these feel good vitamins and minerals from foodstuff or from supplements. In the United Kingdom, over 20,000 premature deaths per year are associated with too much alcohol drinking; thus equating reduction of stress via alcohol consumption to stress reduction through death [30,31].

The body responds to stress through a hormone system, the hypothalamic-pituitary adrenal (HPA) axis. Stimulation of the system results in the secretion of stress hormones such as glucocorticoids. Chronic excessive glucocorticoid secretion can have adverse health effects, such as Cushing's syndrome, premature and/or exaggerated aging. [32] Alcohol intoxication activates the HPA axis and results in elevated glucocorticoid levels, which is actually ascribed to alcohol's delightful effects. One of the problematic issues regarding alcohol intake among youth is the myth whether the youths' lifestyles are carried over into later life or not [33].

A significant proportion of our respondents admitted to have used LSDs for beautification (10\%) and preventing unwanted pregnancies (1\%). Using cosmetics for skinbleaching/lighten or beautification with the perception that light skinned people become more attractive/beautiful, this is a myth that needs to abandoned. The cultural and lifestyle determinants of toxic heavy metal exposure and the greater susceptibility of African populations to environmental metal poisoning were at the peak in early 2000. Skin-bleaching products contain at least one of the three bleaching agents: hydroquinone, corticosteroids or/and mercury. [32,34] Despite mercury and hydroquinone-containing cosmetic and household consumer products, such as skin-bleaching, being banned by regulatory authority, such products are clandestinely sold in Tanzania and other neighboring countries. Usage of LSDs for beautification purpose is more prominent in females than males, which is not unexpected attitude.

Extended use of contraceptive pills for birth control or preventing unwanted pregnancy might also have negative consequences, since progesterone/estrogen pills have also been associated with development of cancers. A combination of hormonal contraceptives is associated with an increased cardiovascular risk including: a small increased risk of venous and arterial thrombosis $[35,36,37]$. The reported adverse effects include breakthrough bleeding and amenorrhea. It also has been shown that contraceptives such as norethisterone (or norethindrone) that is also clinically indicated for hormone replacement therapy or to prevent menorrhagia, has now been used by women in order to delay menstruation during holidays or other events, making it a LSD as well [11].

Sleeplessness has similarly been accepted as a health problem. About 7 (7.7\%) students were regular consumers of benzodiazepines, which they said were very useful in controlling their sleep patterns and for controlling examination anxiety. Sleep deprivation is a social problem that can have huge impacts both at individual and societal levels. Studies have shown that sleeps disorders, sleep deprivation and impaired cognitive performance become significant when they impact upon the ability of an individual to negotiate the demands of their everyday life. $[13,26]$ Therefore, use of substances/drugs that can change sleep patterns could negatively affect the user. It appears that, when drug therapy is available, physicians are less willing to consider non-drug treatments, even when there is no evidence that pharmacotherapy is superior. [2] Therefore, LSDs are currently used to treat 'lifestyle illnesses', which can be considered as diseases arising through 'lifestyle choices', such as obesity, smoking and alcoholism. [3,21] Substances-containing caffeine have been customarily used for sleep patterns control by students ever since. Caffeine is central nervous system (CNS) stimulant, which keeps someone alert, and thus 
prevent students from fatigue. However, it is unusual to use other "chemicals" or drugs that alter sleep patterns. Besides, caffeine is not categorized as LSD.

The prevalence rate of LSDs usage might switch over time from lifestyle to mainstream use. The implication of this may dwell not only on consumers but also pharmaceuticals manufacturers and policy makers; hence affecting moral, integrity and authenticity of our societies. The present study shows that most of the students who used LSDs apparently had no good reasons for using LSDs; influence from friends or family and need to overcome stress and fear were the vague reasons. Our study showed that some respondents had been using at least one of the LSDs for various reasons; combining alcohol and drugs such as diazepam, which may lead to serious CNS depression as both drugs are CNS depressants. [6,15,37] This study has uncovered an unusual issue in our universities/communities, that is the use of drugs for alteration of sleep patterns among respondents. Easy availability of benzodiazepines, such as diazepam, as over the counter drugs, can contribute to this observation.

Lastly, being a pioneer study that was conducted for short period of time and only involving university students could be one of the drawbacks of this study. It is therefore recommended that more time be allocated in future study that will involve larger sample size with more heterogeneous population to yield more conclusive findings.

\section{Conclusions}

Increasing availability of medicine/drugs particularly LSD capable of altering appearance, physical and mental capabilities/characters, is changing social fabric of cultures among youth and poses serious health challenges. Indiscriminate use of LSDs may result into severe adverse effects, abuse potential of LSDs and other safety concerns.

About 29\% of the respondents were LSDS users; however majority (66.5\%) confessed that most of LSDs were unnecessarily used. Because apparently LSDs are purchased without prescription from regular drugs stores, this serve as an indicator of easy availability of drugs, LSDs inclusive. Therefore, the present study provides useful information that could be helpful in elaborating intervention methods to alleviate the problem of LSD usage among the youths and general public at large.

\section{Acknowledgements}

Authors acknowledge the financial support from the Ministry of Education and Vocational Training-Tanzania for making this study possible. They also appreciate for the cooperation given by the respondents and the MUHAS and UDSM authorities.

\section{References}

[1] Rahman, S., Gupta, V., Sukhlecha, A., \& Khunte, Y. Lifestyle drugs: Concept and impact on society. Indian journal of pharmaceutical sciences, 72 (4), 409. 2010.
[2] Everitt, D.E., Avorn, J., Baker, M.W. Clinical decision-making in the evaluation and treatment of insomnia. American Journal of Medicine, 89:357-62. 1990.

[3] Gilbert, D., Walley, T., and New, B. Lifestyle medicines. British Medical Journal, 321 (7272), 1341, 2000.

[4] Flower, R.J. Lifestyle and non-medical use of drugs. In: Rang HP. Dale MM, Ritter JM. editors. Rang and Dale's pharmacology. $6^{\text {th }}$ ed. London: Churchill living stone; 2007, 765-9.

[5] Ashworth, M., Clement, S., \& Wright, M. Demand, appropriateness and prescribing of 'lifestyle drugs': a consultation survey in general practice. Family Practice, 19 (3), 236-241, 2002.

[6] Young, S.N. Lifestyle drugs, mood, behavior and cognition. Journal of Psychiatry Neuroscience, 28 (2): 87-9, 2003.

[7] Moynihan, R., Heath, I., Henry, D. selling sickness-The pharmaceutical industry and disease mongering. British Medical Journal, 324: 886-91, 2002.

[8] Outram, S.M. The use of methylphenidate among students: the future of enhancement? Journal of Medical Ethics 36: 198-202, 2010.

[9] Powell, R., Kahane, G., \& Savulescu, J. Evolution, Genetic Engineering, and Human Enhancement. Philosophy \& Technology, 25 (4), 439-458, 2012.

[10] Fox, N. J., \& Ward, K. J. Pharma in the bedroom... and the kitchen.... The pharmaceuticalisation of daily life. Sociology of health \& illness, 30 (6), 856-868, 2008.

[11] Shakespeare, J., Neve, E. and Hodder, K. Is norethisterone a lifestyle drug? Results of database analysis, British Medical Journal, 320, 291, 2000.

[12] Aronson, J.K. From prescription-only to over-the-counter medicines ('PoM to P'): time for an intermediate category. Br Med Bull 90: 63-69, 2009.

[13] Coveney, C.M. Awakening expectations: Exploring social and ethical issues surrounding the medical and non-medical uses of cognition enhancing drugs in the UK (Doctoral dissertation, University of Nottingham), 2010.

[14] Sapolsky, R.M. Why stress is bad for your brain. Science, 273: 749-750, 1996.

[15] Lucke, J.C., Bell, S.K., Oatridge, B.J., and Hall, W.D. Academic doping or Viagra for the brain? The history of recreational drug use and pharmacological enhancement can provide insight into these uses of neuropharmaceuticals. EMBO Report, 12 (3): 197201, March 3, 2011.

[16] Fox, N. J., Ward, K. J., \& O'Rourke, A. J. The 'expert patient': empowerment or medical dominance? The case of weight loss, pharmaceutical drugs and the Internet. Social Science \& Medicine, 60 (6), 1299-1309, 2005.

[17] Flower, R. Lifestyle drugs: pharmacology and the social agenda. Trends in Pharmacological Sciences, 25 (4), 182-185, 2004.

[18] Edwards, I. R., \& Aronson, J. K. Adverse drug reactions: definitions, diagnosis, and management. The Lancet, 356 (9237), 1255-1259, 2000.

[19] Use, Food, Herbal Use, Toxicity Side-effects, and Warnings Contra-indications. "Martindale: the complete drug reference." 2007.

[20] Rose SPR. 'Smart Drugs': Do they work? Are they ethical? Will they be legal? Nature Reviews Neuroscience, 3: 975-9, 2002.

[21] Fox, N.J. and Ward, K.J. Health identities: from expert patient to resisting consumer, Health, 10, 4, 461-79, 2006.

[22] Shrier, L. A., Emans, S. J., Woods, E. R., \& DuRant, R. H. The association of sexual risk behaviors and problem drug behaviors in high school students. Journal of Adolescent Health, 20 (5), 377383, 1997

[23] Little, A., \& Roberts, S.C. Evolution, appearance, and occupational success. Evolutionary psychology: an international journal of evolutionary approaches to psychology and behavior, 10 (5), 782-801, 2012.

[24] Ross, R., Freeman, J. A., \& Janssen, I. Exercise alone is an effective strategy for reducing obesity and related comorbidities. Exercise and sport sciences reviews, 28 (4), 165-170, 2000.

[25] Lexchin, J. Lifestyle drugs: issues for debate, Canadian Medical Association Journal, 164, 10, 1449-51, 2001.

[26] Coveney, C. M., Nerlich, B., \& Martin, P. Modafinil in the media: Metaphors, medicalisation and the body. Social Science \& Medicine, 68 (3), 487-495, 2009.

[27] Himle, J. A., Abelson, J. L., Haghightgou, H., Hill, E. M., Nesse, R. M., \& Curtis, G. C. Effect of alcohol on social phobic anxiety. American Journal of Psychiatry, 156 (8), 1237-1243, 1999. 
[28] Burke, R.S., and Stephens, R.S. Social anxiety and drinking in college students: A social cognitive theory analysis. Clinical Psychology Reviews, 19 (5): 513-530, 1999.

[29] Hallfors, D. D., Waller, M. W., Bauer, D., Ford, C. A., \& Halpern, C. T. Which comes first in adolescence-sex and drugs or depression? American Journal of Preventive Medicine, 29 (3), 163-170, 2005

[30] Rehm, J., Sulkowska, U., Mańczuk, M., Boffetta, P., Powles, J., Popova, S., \& Zatoński, W. Alcohol accounts for a high proportion of premature mortality in central and eastern Europe. International journal of epidemiology, 36 (2), 458-467, 2007.

[31] Harrison, L., \& Gardiner, E. Do the rich really die young? Alcohol-related mortality and social class in Great Britain, 1988-94. Addiction, 94 (12), 1871-1880, 1999.

[32] Spencer, R.L., and Hutchison, K.E. Alcohol, aging, and the stress response. Alcohol Research \& Health 23 (4): 272-283, 1999.
[33] Webb, E., Ashton, C. H., Kelly, P., \& Kamali, F. (1996). Alcohol and drug use in UK university students. The lancet, 348 (9032), 922-925.

[34] Blay, Y.A. Skin bleaching and global white supremacy: By way of introduction. Journal of Pan African Studies, 4 (4), 2011.

[35] Lewis, K. M., Harris, S., Camp, C., Kalala, W., Jones, W., Ellick, K. L. \& Younge, S. The Historical and Cultural Influences of Skin Bleaching in Tanzania. In The Melanin Millennium Springer Netherlands, 2013, 19-38.

[36] Archer, J., Archer, D. "Oral contraceptive efficacy and antibiotic interaction: a myth debunked." Journal of American Academy of Dermatology, 46 (6): 917-23, 2002.

[37] Brito, M.B., Nobre, F., Vieira, C.S. "Hormonal contraception and cardiovascular system." Arquivos brasileiros de cardiologia 96 (4): e81-9, Apr 2011. 